\title{
MAPPING AS A TOOL FOR BIOMATERIALS STUDY CONTENT HARMONIZATION WITH SIGNIFICANT RESEARCH FINDINGS
}

\author{
Rudīte Koka \\ Riga Stradins University, Latvia \\ Nora Jansone-Ratinika \\ Riga Stradins University, Latvia \\ Tatjana Koke \\ Riga Stradins University, Latvia \\ Matīss Sīlis \\ Riga Stradins University, Latvia \\ Raimonds Strods \\ Riga Stradins University, Latvia
}

\begin{abstract}
Riga Stradins University (RSU) has almost 70-year-experience in implementing health care and 20-year-experience social science studies. RSU has more than 9000 students, $26 \%$ of whom are international students. International recognition is enabled by direct correlation between quality of studies and competitiveness of graduates. Quality of studies is being systematically improved and mapping of the study results is a significant tool in implementation of the process. A mapping system created by RSU makes it possible to analyse study programmes, study course connections, succession, implementation, novelty and correspondence to the professional standard requirements, identifying level of alignment between graduate outcomes, study programme, study course results and study activities. Consequently, it is possible to trace synergy between a study programme and development tendencies of the discipline. With rapid developments in the medical industry, discussions about the use of biomaterials are being raised, which is an essential component in strategical specialisation fields in Medicine and Dentistry in RSU. Biomaterials are used in many of today's medical devices, including artificial skin, blood vessels, hearts, pacemakers, dental fillings, wires, plates and pins for bone repair, total artificial joint replacements.

The aim of the research is to study the conformity of biomaterials content acquisition in RSU Dentistry study programme to significant research findings.
\end{abstract}


Qualitative methodology is used in the research: study course learning outcomes mapping, interviews with field experts, observation of the course, study programme and course leaders and student focus group.

Upon evaluation of the obtained research results, the following conclusions are proposed:

- The theme 'biomaterials' is very topical in Dentistry study programme and its significance is ascertained to have a tendency to increase.

- Balanced distribution of biomaterials content in the study programme is needed to ensure more successive and systemic acquisition of study results.

- To foster students' readiness to work with biomaterials in a clinic, improvement in cooperation of the faculty is necessary which would facilitate the appropriateness of specific content to Dentistry sub-sectors.

Summarising the research results, it can be concluded that study course learning outcomes mapping and interviews with education actors involved in the study programme, have helped to discover the essence and range of biomaterials content acquisition, succession, reciprocal links at study course level and appropriateness of content to significant research findings. The obtained results have been conceptualised, communicated to various target groups and update of Dentistry study programme is based on them.

Keywords: biomaterials, acquisition of study results, mapping, dentistry.

\section{Introduction}

RSU is one of the most modern universities in the Baltics and enjoys a high reputation for its study quality on an international level.

One of the cornerstone principles of the quality assurance at RSU is safeguarding the relevance of the study content to industry trends and requirements. To assure this relevance, the study programme content and learning outcomes have to be reviewed and updated on an ongoing basis. To institutionalise this process of curriculum review, RSU has implemented practice of building and maintaining curriculum maps.

Curriculum mapping is a process of developing a visual map of all courses in the curriculum and evaluating course content to determine if any gaps or excessive overlap exist, and to ensure all courses meet the study programme learning outcomes (Harden, 2001; Plaza et al., 2007). Curriculum map is a tool that allows the stakeholders to visualise the curriculum by ordering the relationships between various elements of the curriculum. Traditionally the study programme content is managed by academics in isolation from each other, rarely working together to achieve the programme learning outcomes. This creates a risk that some courses will overlap and address similar learning outcomes multiple times, while not addressing some of the learning outcomes at all. Curriculum map assists in identifying these overlaps and gaps in the curriculum and make them transparent to the stakeholders (Steketee, 2015). 
In 2018, RSU study programme directors mapped learning outcomes at the study programme level to learning outcomes at the study course level, creating curriculum maps for each of the RSU study programmes. During this process multiple improvements to study programmes were identified. Previous research (Uchiyama \& Radin, 2009; Joyner, 2016) has identified the importance of faculty involvement in the mapping process for buyin and effective implementation of curriculum improvements, therefore a decision to validate the relevance of mapping results with stakeholders was made.

This case study describes how curriculum mapping results were used to identify improvements in biomaterials study content, validate these findings with students, faculty and industry representatives, and achieve consensus on the necessary changes to the curriculum of the dentistry study programme.

The five-year long dentistry study programme provides a platform for the acquisition of the skills required for examination of a patient's oral cavity and teeth, identification of dental problems and for undergoing complex dental treatment. The programme emphasises the importance of first undergoing practice on dental trainer and simulation models prior to working in a clinic in real life conditions. Mapping of the programme learning outcomes indicated potential improvements in the organisation of theoretical content of the study programme related to the use of biomaterials in dentistry.

The complexity of the design of the study programme, the improvement of its implementation and the successful achievement of learning outcomes is determined by the fact that research on biomaterials is developing very rapidly. Experts all over the world are looking for the most successful solutions for developing and synthesizing bone or tissue-like materials. These smart materials can be used to develop innovative third-generation biomaterials (Rey et al., 2011). Third-generation biomaterials show great promise. They are being designed to stimulate specific cellular responses at the molecular level and that involve molecular tailoring of resorbable polymers for specific cellular responses (Hench \& Polak, 2002).

Biomaterials or biocompatible materials are primarily biomimetic materials capable of not only interacting with biomaterials (such as tissues, bones), but also of imitating or even enhancing their functions (Hench \& Polak, 2002).

Understanding the biological formation of different mineralized structures could lead to innovative approaches toward engineering novel scaffolds providing new therapeutics. Additionally, unlike other biomineralized tissues, such as bone and dentin, mature enamel is acellular and does not reabsorb or remodel. As a result, enamel regeneration cannot 
occur in vivo following the failure and is therefore an attractive target for future biomimetic and therapeutic approaches (Roveri \& Iafisco, 2010).

Contemporary dentistry applies several types of barrier membranes and graft materials used in guided bone regeneration (GBR). Each has its advantages and disadvantages. Features of materials daily use in dentistry and in maxillofacial surgery were emphasized (Rodella et al., 2011).

Biomaterials are widely used as implant materials in dentistry. An ideal implant material should be biocompatible, with adequate toughness, strength, corrosion, wear and fracture resistance (Osman \& Swain, 2015).

The main goal of all these sectoral studies is to create biomaterials that are as compatible with human tissues as possible, not only to perform their functions, but even to improve them.

\section{Aim of the Study}

The development of the sector and professional performance in practice correlate directly with the quality of the study programme, which logically justifies the goal of the research to study the correspondence of biomaterials content acquisition in RSU study programme "Dentistry" to significant research findings.

\section{Materials and Methods}

In the theoretical part of the study, the scientific literature provides a justification for mapping of learning outcomes as a tool for the analysis and improvement of the study quality, as well as for the topicality of the biomaterial development research and use in dentistry.

The empirical part of the study includes several stages. The pedagogical research was carried out in RSU study programme of Dentistry from September 2018 to May 2019. Three stages were distinguished in the research plan; in which data were obtained by using various methods (see Figure 1). Stage 1: identification of Biomaterials content in the Study Programme and Study Courses and Mapping of Study Results (Learning Outcomes). The resulting understanding of thematic systematisation of biomaterials content related key words and identification of relations between the study results in various study courses. Successively, in Stage 2 the data were obtained in several clusters: structured peer observation of the study courses was made and interviews with field experts were held, and study programme and course leaders focus group was set up. As a result, the opinion of the teaching staff on the use of various materials, including biomaterials, in dentistry, on the scope of learning, succession, topicality and possibilities to implement the content according to the latest trends in science in various study courses 
was summarised. During Stage 3, the final stage, a student focus group was formed. This stage of the study summarises the students' opinion on learning about various materials used in dentistry, including biomaterials (their diversity, properties, usability, topicality, etc.) in various study courses.

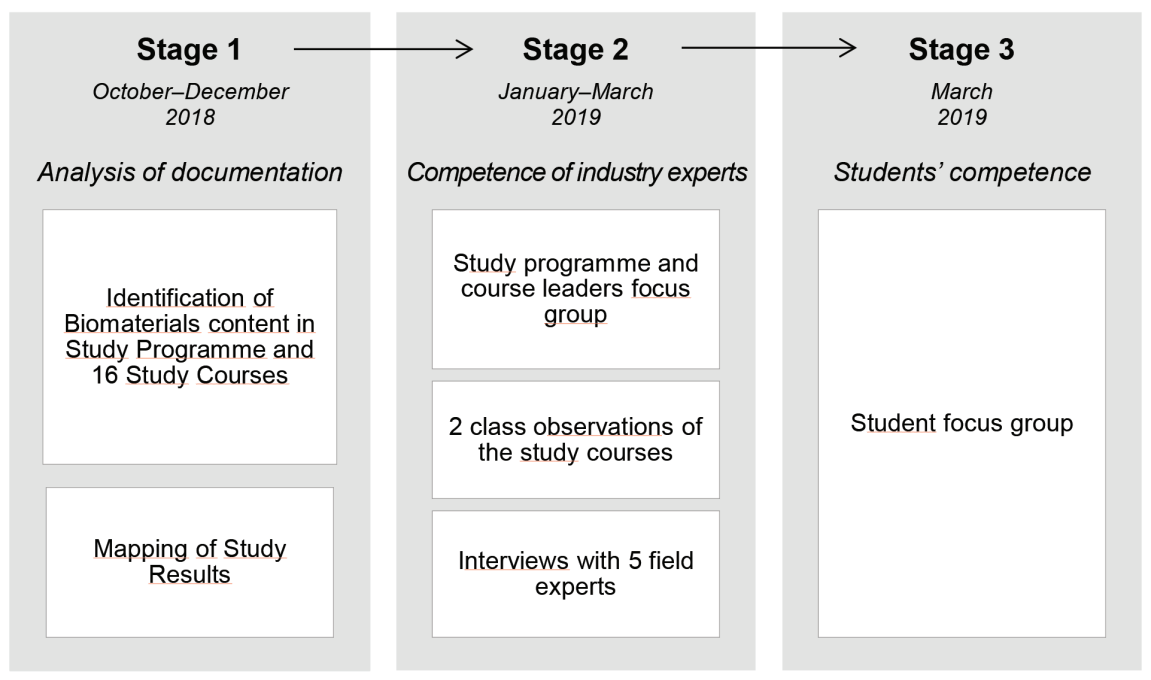

Figure 1. Stages in conducting the study

The study was conducted using the qualitative research approach with data being obtained through: mapping of study courses, interviews with industry experts and the Head of the study programme, focus group discussions with leaders of study courses and students and structured pedagogical observation. The data obtained in the study were recorded in audio recordings, transcripts were prepared and Microsoft Excel 2016 program was used for the analysis. Personal data protection was ensured in data collection, processing and analysis.

As a result of the mapping, 16 study courses were identified in which students successively acquire the theoretical understanding of biomaterials needed for further development of skills in preclinical and clinical study courses. As a result of the mapping, a report material was created (Microsoft Excel 2016) on the basis of the following criteria: the department teaching the study course, the leader of the study course and the lecturers involved in the implementation of the study course, the necessary prerequisites for the students, the aim of the study course, the period needed to learn the content of the study course, the number of credit points, the main topics of lectures and practical classes, learning outcomes: knowledge, skills and competence, independent work of students, assessment criteria and the type of final examination. 
These study courses were grouped according to the main areas of the dental sector: cariology, endodontology, periodontology, surgery and prosthetic. In order to successfully fulfil the further tasks of the study, the mapping results were presented in the focus group discussion for the Head of the study programme and for the leader of the study course "Biomaterials in Oral and Maxillofacial Surgery". A joint analysis of the obtained results lead to creation of interview questions for the lecturers of the study courses and for the discussion of the student focus group, and to selection of the study courses for pedagogical observation, for which a structured protocol was drawn up. For an indepth analysis of the mapping results, an expert from each of the above mentioned areas was invited to a structured interview. Five students from the second, third, fourth and fifth year of study, that have acquired or are currently studying one of the study courses identified as a result of mapping, participated in the student focus group. Students applied on a voluntary basis.

\section{Results}

The data obtained during the study show that the mapping approach and the system used at RSU allows analysing and identifying study programmes, links between the study courses, their succession, implementation, novelty and compliance with the requirements of the occupational standard, thus providing valuable information for the analysis of the quality and successive improvement. The results structured according to data clusters were obtained in the study. As a result of the mapping, a hierarchical system of 16 study courses (see Figure 2) was created reflecting the successive learning of the theoretical and practical biomaterials content in RSU study programme "Dentistry". Acquisition of all the content in the study programme is organised in accordance with the key areas of the sector, in which the necessity for learning the biomaterials content was identified: cariology, endodontology, periodontology, surgery and prosthetic, - The table shows which study courses incorporate the topical and sector-specific theoretical material on biomaterials. For example, the study course "Preclinical and Clinical Course in Endodontics" includes the following learning outcome: the student will name and describe endodontic materials. Whereas, the learning outcome for the study course "Preclinical Course in Operative Dentistry I" is to fill the established cavities with adequate dental filling material, applying a sequence of manipulations corresponding to the material used. So, different biomaterials are used in different areas of dentistry. Figure 2, however, shows which theoretical material acquired during preclinical 


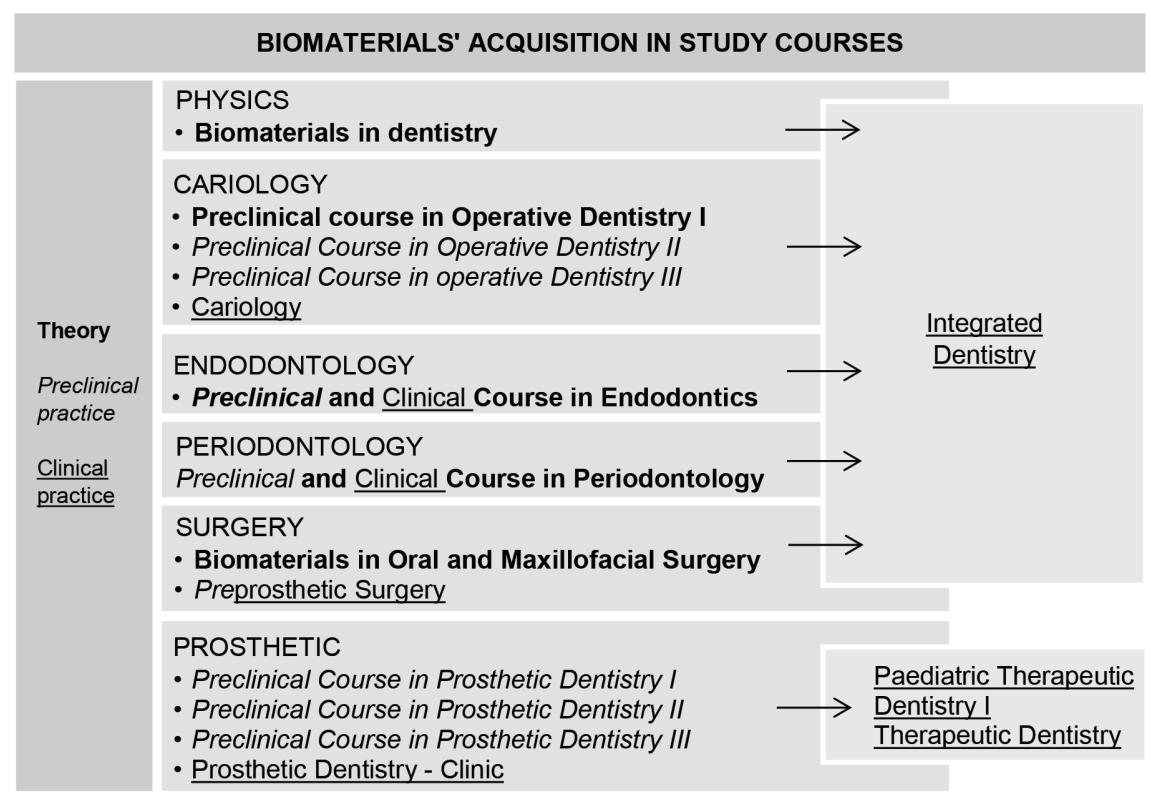

Figure 2. Curriculum Mapping resulted in a hierarchical system of study courses

study courses should be used for further development of their skills, how to select the appropriate biomaterials and use them to treat the patient. For example, the learning outcome in the preclinical part of the study course "Preprosthetic Surgery" requires that the student is able to choose the right method of implantation and performs dental implantation in an artificial jaw; and successively, in the clinical part of the course the student will do clinical case planning and surgical treatment and prosthetics to a patient. The first study course devoted to this topic in the study programme "Dentistry" is "Biomaterials in Dentistry", which students undertake during the second semester of the first year of study in the amount of one credit point. This study course is taught at the Department of Physics in cooperation with the lecturers involved in the dentistry programme. On completion of the study course, students will have acquired the competence to evaluate physical properties of biomaterials and their use. The learning outcomes suggest that students will use the terms used in physics correctly, including those related to biomaterials; will describe the properties of biomaterials and the physical processes that characterise them; will define methods for determining the physical properties of biomaterials; will have acquired skills to describe the regularities of the deformation theory for the comparative characterisation of the mechanical properties of different biomaterials and will be able to predict the behaviour of biomaterials under the influence of various factors (static and dynamic load, changes in 
external factor parameters). The study course "Biomaterials in Dentistry" is planned in the format of four lectures and two practical classes with a final examination in the form of a semester test on biomaterials.

The table shows that successful learning of the four study courses included in the Cariology direction leads students to the acquisition of the study courses "Paediatric Therapeutic Dentistry I" and "Therapeutic Dentistry" during the $4^{\text {th }}$ year of study, where the learning outcome is to evaluate the correlations and integrate the knowledge acquired in other medical and dental sectors into diagnosing, prognosticating and treating caries, pathology of hard dental tissues and pulpal and periodontal pathology both in children and adults, which means that they are able to clinically accept and treat patients. Whereas, successful completion of the study courses of the four main areas allows the student to achieve successively the level of the fifth year of study, which includes the study course "Integrated Dentistry" and the learning outcome is to evaluate the patient's dental health in general and provide all the necessary treatment according to their level of competence: complete full diagnostics, develop a treatment plan and complete the treatment successfully. Thus the achieved result by the student conforms to Article 1.58.3 of the occupational standard regarding the professional competence needed for carrying out the professional activity (National Centre for Education, 2012).

In the mapping process, when analysing the use of the concept biomaterials, it was found that different concepts were used in the study course descriptions: various filling materials, sealing with various materials, available materials, applicable materials. Therefore, the interviews clarified the industry experts' understanding of the concept of biomaterials and its place in a larger thematic block.

In discussing the mapping results with the Head of the study programme and the leader of the study course "Biomaterials in Oral and Maxillofacial Surgery", the viewpoint was expressed that a deeper analysis was needed to improve the proportional distribution of the content in the study programme and to achieve a more successive and systemic acquisition of the learning outcomes, taking into account the fact that six RSU departments and at least 51 lecturers are involved in the implementation of the topic biomaterials. Large number of the involved lecturers demands a unified conception of the content implementation. During the discussion, the Head of the study programme noted that a number of individual conversations with students took place in the previous academic year and the opinion of students on the necessity to improve the content acquisition was expressed.

Analysing the data obtained in interviews and the focus group, it can be concluded that the opinion of both lecturers and students on the definition 
of biomaterials coincides with that defined in the theoretical literature. Colleagues emphasized that they are materials that are compatible with the human body and their diversity is very wide, as well as drew attention to the fact that each area of dentistry has its own material specificity and different types of biomaterials, for example, one type of biomaterials may be used in oral, facial and jaw surgery, but other biomaterials in periodontology and endodontics.

“...We have divided into very small sections, each course in dentistry speaks about its kind of biomaterials...there is enormous number of materials, each specific case requires its own material, therefore creating a special course devoted to biomaterials would be quite useless."

All respondents, both lecturers and industry experts and students, agree that the topic biomaterials is very topical.

“..Very topical. In my opinion, the most topical subject in medicine, because we will use them in prosthetics, implantation. we can help people more and more."

Considering that the research and use of biomaterials in medicine have been developing rapidly, lecturers follow the latest trends in this field and include this content in their study courses by improving prosthetic techniques and devices, studying interactions between implants and biological tissues, and so on (Bruschi et al., 2015). However, both lecturers and students admit that not all study courses are currently fully implemented. Students particularly emphasize that they would like to have general study courses that are more focused and more directly linked to dentistry, and in general it is essential to work continuously towards systemically integrating the most topical and latest achievements of the sector into the programme.

In a number of quotes, the students reveal the latest developments in the sector related to biomaterials. "..we could talk about the biological contact between the tissue and prosthesis; look at their cross-section, as well as the interaction between the implants and biological tissues, which would also be useful for us later in surgery."

Some lecturers particularly emphasize succession in learning the content.

"..there are study courses where the topic is discussed at the theoretical level, then the students go to the preclinic and logically the information is supplemented, and in the clinic, too... (..) we need to know what to use.."

Students also acknowledge the importance of gradual and successive acquisition of knowledge and skills; emphasize the importance of relevance of the scope of the content, accurate selection of the content and linkage with the practice. 
“..to learn not about all the possible materials in dentistry, but only about the specific materials we will use in prosthetics, such as linking the materials with the real situation in the patient's mouth, and there are thousands of different adjustments that will have to be considered. It would help, if we more analysed clinical cases."

For the improvement of succession, lecturers and students recommend reviewing the place of the study course "Biomaterials in Dentistry" within the study programme. At present it is included in the 1st year of study together with the content of medical physics and the students have the next contact with this topic only in the 3rd year of study, which makes it difficult to learn the content continuously and consolidate it successively.

“..He learns some sort of theoretical formula, something which is isolated from real life, and then either he learns or does not learn, remembers or does not remember, because at that point it was not important for him and later it is difficult or even impossible to link".

Industry experts admit that the leader of each study course individually makes improvements in the study course, but more careful work is needed in interdisciplinary collegial harmonisation of the content, because mutual cooperation between lecturers is a prerequisite for the preparedness of students to work in the clinic. This is also confirmed by the data obtained from pedagogical observations.

"..we improve the study course every year because we notice some inaccuracies or we realise how we can better teach it"; "..we have not coordinated the biomaterials content among ourselves..."

Both lecturers and students aim to improve the content and process of studies to the search, analysis and use of scientific research, closer links between theory and practice, so that the student can understand the practical applicability of knowledge as early as possible: preparation of biomaterials, testing of physical properties and compatibility with biological tissues.

“..I would be interested, if we are talking about the properties of materials, such as the load resistance or wear, then I would like to test it practically with biomaterials, because it will be important for me to explain it to the patient."

The results of the study demonstrate the importance of research on biomaterials content in the study programme of dentistry. The mapping of study courses and interviews with the educational actors involved in the study programme have allowed to discover the nature and amount of the biomaterials content to be learned, succession, interconnection at 
the level of study courses and the relevance of the topics to major research worldwide. The results obtained are conceptualised and communicated in various target groups and the plan for the improvement of the study programme is based on them.

\section{Conclusions}

The analysis of the results obtained leads to the conclusion that:

1. The biomaterials theme is very topical in the study programme "Dentistry" and its significance is ascertained to have a tendency to increase;

2. Balanced distribution of biomaterials content in the study programme is needed to ensure more successive and systemic acquisition of study results;

3. To foster students' readiness to work with biomaterials in a clinic, improvement in cooperation of the faculty is necessary which would facilitate the appropriateness of the specific content to Dentistry sub-sectors.

The following recommendations are put forward for a meaningful analysis and improvement of the quality of the study process:

1. To improve and organize a regular, systematic communication and cooperation among the stakeholders, to produce a $360^{\circ}$ feedback from lecturers, students, management, support staff and industry representatives;

2. To come to an agreement on common understanding and use of concepts;

3. Based on mapping results, to come to an agreement on meaningful and successive integration of biomaterials content in theoretical, pre-clinical and clinical study courses;

4. To ensure that each course is based on previously acquired knowledge and complements it with the subject-specific content, but does not repeat the previously acquired content;

5. To update biomaterials content according to the latest research.

\section{References}

Bruschi, M., Steinmüller-Nethl, D., Goriwoda, W., \& Rasse, M. (2015). Composition and Modifications of Dental Implant Surfaces. Journal of Oral Implants, Volume 2015, 14 pages. Retrieved from https://www.hindawi.com/journals/joi/2015/527426/.

Harden, J. (2001). AMEE Guide No. 21: Curriculum Mapping: A tool for transparent and authentic teaching and learning. Medical Teacher, 23(2), 123-137.

Hench, L. L., \& Polak, J. M. (2002). Third-generation biomedical materials. Science, 295, 1014-1017. Retrieved from https://www.ncbi.nlm.nih.gov/pubmed/11834817. 
Joyner, H. S. (2016). Curriculum mapping: a before-and-after look at faculty perceptions of their courses and the mapping process. Journal of Food Science Education, 15, 63-99.

Osman, R. B., \&Swain, M. V. (2015). A Critical Review of Dental Implant Materials with an Emphasis on Titanium versus Zirconia. Materials (Basel), 8(3), 932-958. Retrieved from https://www.ncbi.nlm.nih.gov/pmc/articles/PMC5455450/citedby/.

Plaza, C. M., Draugalis, J. R., Slack, M. K., Skrepnek, G. H., \& Sauer, K. A. (2007). Curriculum mapping in program assessment and evaluation. American Journal of Pharmaceutical Education, 71(2), 1-8.

Rey, C., Combes, C., Drouet, C., et al. (2011). Bioactive Ceramics: Physical Chemistry. In P. Ducheyne, K. E. Healy, D. W. Hutmacher, D. W. Grainger \& C. J. Kirkpatrick (eds.) Comprehensive Biomaterials, Elsevier, Amsterdam et al., 1, 187-221. Retrieved from https://www.elsevier.com/books/comprehensive-biomaterials/ducheyne/ 978-0-08-055302-3.

Rodella, L. F., Favero, G., \& Labanca, M. (2011). Biomaterials in Maxillofacial Surgery: Membranes and Grafts. International journal of Biomedical science, 7(2), 81-88. Retrieved from file:///C:/Users/Rudite/Downloads/Biomaterials_in_ Maxillofacial_Surgery_Membranes_an.pdf.

Roveri, N., \& Iafisco, M. (2010). Evolving application of biomimetic nanostructured hydroxyapatite. Nanotechnology, Science and Applications, 3, 107-125. Retrieved from http://citeseerx.ist.psu.edu/viewdoc/download?doi $=10.1 .1 .860 .8544 \& \mathrm{rep}=\mathrm{rep} 1 \&$ type $=$ pdf.

Steketee, C. (2015). Prudentia: A medical school's solution to curriculum mapping and curriculum management Journal of University Teaching \& Learning Practice, 12(4), $1-10$.

Uchiyama, K. P., \& Radin, J. L. (2009). Curriculum Mapping in Higher Education: A Vehicle for Collaboration. Innovative Higher Education, 33(4), 271-280.

Valsts izglititibas satura centrs [National Centre for Education of the Republic of Latviašeit anglisko tulkojumu]. (2012). Zobārsta profesijas standarts [Dentist's Professional Standardšeit anglisko tulkojumu]. Retrieved from https://visc.gov.lv/profizglitiba/ dokumenti/standarti/ps0481.pdf. 